\title{
Vermischte Nachrichten.
}

Ueber die Entdeckung der Variation und def jährlichen Gleichung des Mondes. Von $G$. $A n$ schütz, S. J. (Schloemilch, Zeitschrift für Mathematik und Physik. 31. Jahrgang 5. Heft u. ff.).

Der Verfasser sucht in dieser Abhandlung die folgen. den drei Sätze nachzuweisen:

I. Tycho Brahe kann nicht als Entdecker der jährlichen Gleichung des Mondes gelten.

2. Dagegen gebuhrt Tycho Brahe das Recht, als der selbstständige Entdecker der in Europa bis dahin unbekannten Variation angesehen zu werden, auch für den Fall, dass die nicht unbestrittene Priorität Abul Wefa's begründet sein sollte.

3. Kepler ist der Entdecker der jährlichen Gleichung, war nahe daran, einen sehr genauen Werth fur dieselbe zu bestimmen, und wurde nur durch eine unglückliche -Idee abgehalten, sie auch als Mondgleichung definitiv aufzustellen.
Zur Photometrie der Sonne, von Prof. F. Exner. (Anzeiger der Wiener Akademie der Wissenschaften I 886

Nr. I 7.)

Durch eine Fassende Combination photometrischer Methoden wird es möglich, die Intensität der Sonnenstrahlung direct mit derjenigen einer Normalkerze zu vergleichen. Es hat sich ergeben, dass die Sonne in ihrer Lichtwirkung durch $10^{27}$ Normalkerzen ersetzbar wäre, wenn man das $V$ erhältniss der mittleren Partien des Spectrums als Maass des Verhältnisses der Gesammthelligkeiten gelten läsșt. Als specifische Helligkeit der Sonne, bezogen auf diejenige der Normalkerze, ergiebt sich für den nahezu höchsten Sonnenstand (Mai-Juni) und für die einzelnen Farben:

$\begin{array}{lr}\text { Roth } & 75600 \\ \text { Grün } & 270000 \\ \text { Blau } & 648000\end{array}$

Unter gleicleen Umständen sind die von $\mathbf{1} \square \mathrm{cm}$. der Sonnenoberfäche ausgesendeten Intensitäten in Normalkerzen:

$\begin{array}{lr}\text { Roth } & 18900 \\ \text { Grun } & 67500 \\ \text { Blaul } & 162000 .\end{array}$

\section{Literarische Anzeigen.}

H. Gyldén. Intermediära banor, som vid en gifven tidpunkt ansluta sig till de verkliga med en $\mathrm{kontakt}$ af tredje ordningen. (Intermediäre Bahnen, welche zu einer gegebenen Zeit eine Berührung dritter Ordnurg mit den wirklichen Bahnen eingehen.)

H. Gyldén. Om ett beris for planetsystemets stabilitet. (Ueber einen Beweis für die Stabilität des Planetensystems.)

Beide Abhandlungen sind in den Verhandlungen der Kgl. Akademie der Wissenschaften in Stockholm $1885 \mathrm{Nr} .6$ und r 886 Nr. 3 publicirt.
H. Gravelius. F unfstellige $\log$ arithmisch-trigonometrische Tafeln fur die Decimaltheilung des Quadranten. Mit einem Vorwort von IV. Foerster.

Wenn auch eine aligemeine Einfuihrung der Decimal. theilung des Quadranten in weiter Ferne liegt (falls sie überhaupt je zu erwarten ist), so werden vorliegende Tafeln doch den Astronomen in vielen Fällen bequem sein. Schon die Bremiker'schen fünfstelligen Tafeln, die den Sexagesimalgrad nach Decimalbrüchen theilen, waren und sind noch ein nuitzliches Werk. Zur Unterscheidung der neuen Theilung werden die alten Grad-, Minuten- und Secundenzeichen in horizontaler Lage angewendet.

\section{A $n z e i g e$.}

Die Herren Abonnenten, welche die Astronomischen Nachrichten ferner zu erhalten wünschen, werden ersucht, inre Bestellung und Vorausbezahlung auf den folgenden Band baldmöglichst einzusenden, wofern es der Expedition nicht bekannt ist, dass sie als ständige Abonnenten angesehen werden wollen.

Man pränumerirt bei der Expedition der Astronomischen Nachrichten, Sternwarte Kiel, mit netto I 2 Mark für den Band von 24 Nummern nebst Inhaltsverzeichniss und Register. Für die von der Expedition nummerweise franco versandten Exemplare beträgt der Preis 15 Mark. Einzelne Nummern werden zur Completirung, wenn sie vorräthig sind, zum Preise von 60 Pfennig abge'assen.

Den Hauptdebit dieses Blattes hat, wie bisher, die Buchhandlung von W. Mauke Söhne in IĨamburg.

Geschlossene Bände, von Band roo an, können jederzeit von der Expeditior, Sternwarte Kiel, zum Preise von I 2 Mark pro Band bezogen werden. Von den älteren Bänden sind noch Band 32-99 vorräthig und $2 u$ gleichem Preise bei Prof. C F. W. Peters, Kiel, verkäuflich.

\section{Inhalt:}

Zu Nr. 2760. C.F. Pechith. Cometenheobachtungcn. 385. - C. Wagner. Reobachtingen von Cometen. 39I. - Fohn Tebintt. Observations of Comet is86I at Wimhor, N.S. Whes. 393. -.. F. Porro. Osservazioni di Comete. 397. - F. Bauschinger. Ceber die Heobachtung des Planctei (29) Amphitrite in den Münchener Zonen. 397, -. Vermischte Nachrichten. 399. - Literarische Anzeigen. 399. Anzeige. 399 . 